\title{
Correction to: Advanced fabrication and multi-properties of aluminium hydroxide aerogels from aluminium wastes
}

\author{
Thenappa S. Sp ${ }^{1}$ Phuc T. T. Nguyen ${ }^{1}$ - Nga H. N. Do ${ }^{3}$. Duyen K. Le ${ }^{1} \cdot$ Quoc B. Thai $^{1} \cdot$ Phung K. Le $^{3}$. \\ Nhan Phan-Thien ${ }^{1} \cdot$ Hai M. Duong ${ }^{1,2}$
}

Published online: 19 March 2021

๑) Springer Japan KK, part of Springer Nature 2021

\section{Correction to: \\ Journal of Material Cycles and Waste Management https://doi.org/10.1007/s10163-020-01169-1}

In the original publication of the article, the third affiliation "Faculty of Applied Sciences, Ton Duc Thang University, Ho Chi Minh City, Vietnam" and the email address "duongminhhai@tdtu.edu.vn" should be removed from the corresponding author "Hai M. Duong". The correct affiliations are given in this correction.

Publisher's Note Springer Nature remains neutral with regard to jurisdictional claims in published maps and institutional affiliations.

The original article can be found online at https://doi.org/10.1007/ s10163-020-01169-1.

Hai M. Duong

mpedhm@nus.edu.sg

1 Department of Mechanical Engineering, National University of Singapore, Singapore, Singapore

2 Cuu Long University, Vinh Long, Vietnam

3 Faculty of Chemical Engineering, Ho Chi Minh City University of Technology (HCMUT), 268 Ly Thuong Kiet Street, District 10, Ho Chi Minh City, Vietnam 